\title{
Steam Generator for External Resistances
}

\section{José Luis Hernández Corona, Ernesto Mendoza Vázquez, Hilda Sánchez Lima, Verenice Fragoso Parra, Guadalupe Adriana Espinoza Peralta, José Armando Olivares Bautista}

\author{
Technological University of Tlaxcala. \\ DOI: 10.29322/IJSRP.10.11.2020.p10759 \\ http://dx.doi.org/10.29322/IJSRP.10.11.2020.p10759
}

Abstrac - This document presents the design and construction of an water tube type steam generator, which will be used for drying the production process of a paste for children's soaps and for people with dry skin, this project is carried out within the facilities of the Technological University of Tlaxcala, in the Industrial Maintenance Engineering career.

This project is based on theoretical foundations related to the mechanical design of the equipment by finite element, with the application of Solidword in simulations to verify the reliability of the tank structure, the assembly study, the analysis of efforts inherent to the process to which it is found. The equipment has been subjected, performing operational tests to locate faults and also correct them to avoid possible accidents and losses in the product to be made.

This work makes an important contribution to the development of research, since there are no methods similar to the one proposed, to the extent that it will allow the drying of the paste for the preparation of said soaps.

Index Terms- steam generation, heat transfer, combustion process, temperature, pressure

\section{INTRODUCTION}

The chemist Antoine Lavoiser said that matter is neither created nor destroyed, but transformed, and man, in his desire to make better use of the energy that is extracted from nature, to improve and guarantee his quality of life, has originated various ways to do it for a long time, but uses part of the same energy to achieve it, with various devices, systems and / or equipment. [1]

This way of transforming the chemical energy of a fuel into heat energy is carried out in a device called a boiler or steam generator.

This publication is licensed under Creative Commons Attribution CC BY.

http://dx.doi.org/10.29322/IJSRP.10.11.2020.p10759
Boilers or steam generators are industrial facilities that, by applying the heat of a solid fuel [2], liquid or gaseous, vaporize water for a wide variety of applications, among which are:

- Heating in industrial processes

- The production of electrical energy

The boiler is a closed container that generates water vapor at pressures above atmospheric, absorbing the heat produced by combustion in the home. The temperature of the liquid rises until it reaches vaporization and remains constant while the liquid turns into vapor. Once the boiling temperature is reached, the operating pressure continues the supply of heat and vaporization begins without temperature variation. As long as there is liquid to evaporate, the mixture of steam and liquid is called wet steam, if the heat supplied is such that the temperature of the steam is the vaporization temperature, it is called dry saturated steam. The heat supplied to carry out this transformation is known as the heat of vaporization. [3]

The steam generator is made of a stainless steel tubular with a height of $50 \mathrm{~cm}$, a diameter of $33 \mathrm{~cm}$, an electrical resistance for heating it, as well as a layer of fiberglass for protection, a sheet cap, this has temperature and pressure gauges

\section{STEAM GENERATOR}

Since ancient times the role of the engineer has been basically the same, trying to know and interpret the mechanisms of nature in order to modify it at the service of man. To do this, he has used his knowledge, intuition, experience and the natural means that he has available at all times. With the great computing power that one has these days, the engineer has great advantages to be able to carry out his mission and address more ambitious challenges every day in solving new problems, whose political, economic, scientific or 
technological aspects can have a greater impact on improving the quality of life of man. [4]

A steam generator is an equipment whose objective is the generation of water vapor, which is produced through the transfer of heat from the combustion process, steam generators are the combination of a boiler and a super heater, being a closed container in which, by means of the heat produced by a combustion process, the liquid water in its interior is transformed into steam at a pressure greater than atmospheric. [5]

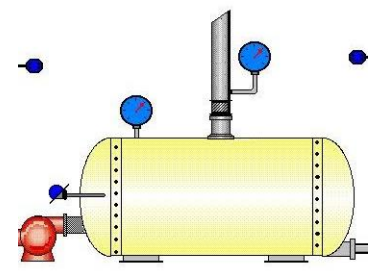

Figure 1 Steam generator

\section{HEAT TRANSFER}

Heat transfer is the process by which energy is exchanged in the form of heat between different bodies or between different parts of the same body that are at different temperatures, the transfer of heat occurs from a warmer body to a colder one until the bodies and their environment reach thermal equilibrium. [6]

Heat is transferred by convection, radiation or conduction, when there is a temperature difference between two objects in proximity to each other, the heat transfer cannot be stopped; it can only be slowed down.

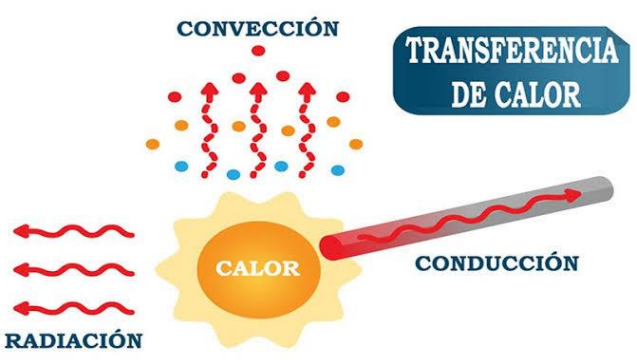

Figure 2 Heat transfer

Steam generators are used for industrial processes such as generating hot water, bringing liquids to their boiling point, evaporating products or drying systems, according to their principle of operation and construction they are classified between. [7]

\section{Firetube}

They are those in which the water circulates inside the tubes and the combustion fumes outside them

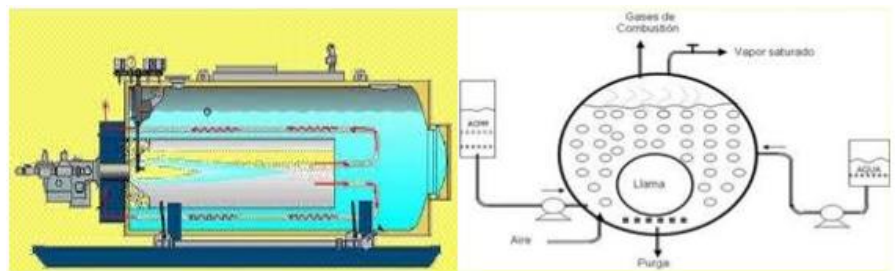

Figure 3 Firetube generator

Water tube

They are those in which the water circulates inside the tubes and the combustion fumes outside the tubes.

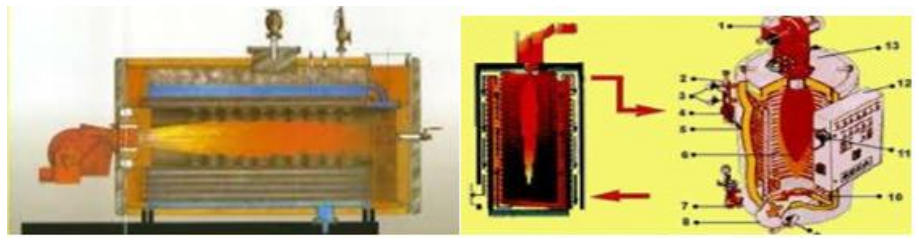

Figure 4 Water tube generator

Among these, the main difference is the way of evaporating the working fluid using the same principle, but a different process, although water-tube steam generators have greater steam production than fire-tube steam generators, however both designs are different. A firetube generator that passes coils at high temperatures within a working fluid can be much easier to build, but a generator that passes fluid through the same coil and encounters high temperatures outside of it will generate more steam at higher pressure as is the case with water tubes.

\section{COMBUSTION PROCESS}

The combustion process, which takes place in the burner of the steam generator, which transforms the chemical energy of the fuel into thermal energy through activation energy. 


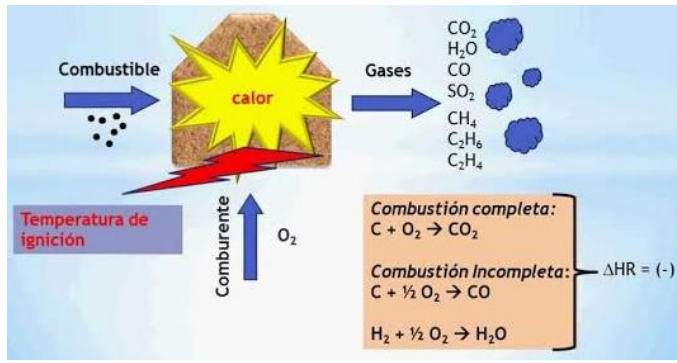

Figure 5 Combustion process example

\section{GENERALITIES}

The steam generator is an equipment that consists of different elements for the production of water vapor and this prototype consists of a tubular made of stainless steel tube, and a stainless steel plate with four holes that have the function of the steam outlet, and inputs from temperature and pressure gauges.

Among the current aids for the practice of Engineering is Finite Element Analysis (FEA, for its acronym in English) implemented in various software such as ANSYS, COMSOL and SolidWorks (CosmoWorks).

\section{SCHEDULE OF ACTIVITIES}

\begin{tabular}{l|l|l|l|l|}
\hline \multirow{2}{*}{ ACTIVITY } & \multicolumn{3}{|c|}{ SCHEDULED EXECUTION DATE } \\
\cline { 2 - 5 } & $\begin{array}{l}\text { January February } \\
\text { March }\end{array}$ & April & $\begin{array}{l}\text { May- } \\
\text { Jun }\end{array}$ & $\begin{array}{l}\text { July- } \\
\text { August }\end{array}$ \\
\hline $\begin{array}{l}\text { System design and finite } \\
\text { element modeling }\end{array}$ & & & & \\
\hline Purchase of materials & & & & \\
\hline Building & & & & \\
\hline Tests & & & \\
\hline
\end{tabular}

\section{DESIGN AND MODELING.}

For heat transfer, the FEA was used, which facilitates the calculation of temperature distributions and air movement by natural convection. Figure 6 shows respectively the temperature and heat flow contour in a steady state configuration, showing the deformations when there is vapor pressure.

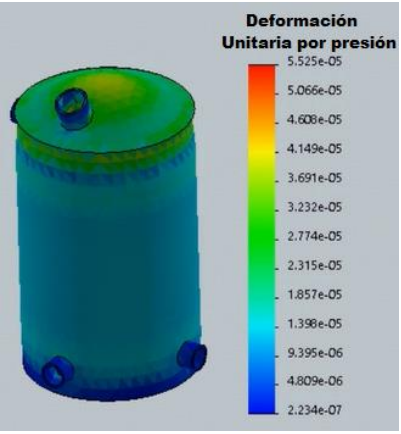

Figure 6Unit pressure of steam
Figure 7 shows the stress concentration at a point, which allows us to observe the critical point, where the maximum steam pressure accumulates, showing that the critical point is the upper part of the steam generator.

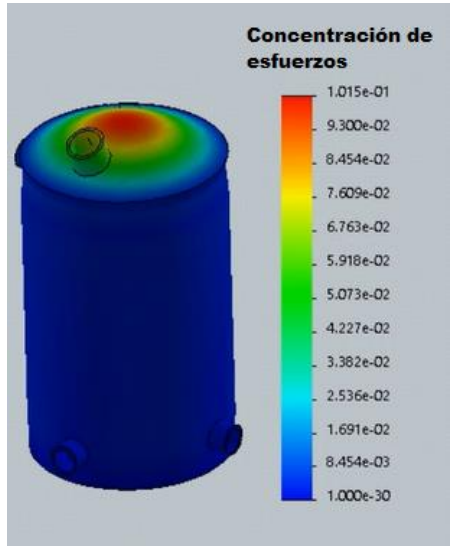

Figure 7 Concentration of efforts

Figure 8 shows the prediction of the life of the proposed component under critical conditions, determining the critical loads that it must withstand, useful for determining direct calculations of structural strengths at the different pressure concentration points.

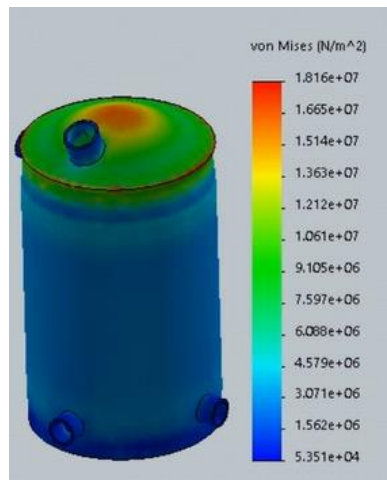

Figure 8 Residual stresses

III. MATERIAL'S LIST

\begin{tabular}{|c|c|c|c|}
\hline MATERIAL & DESCRIPTION & IMAGE & $\begin{array}{c}\text { TOTAL } \\
\text { COST } \\
\$\end{array}$ \\
\hline Fiberglass & $\begin{array}{l}1 \mathrm{~m}^{2} \quad \text { fiberglass } \\
\text { shee }\end{array}$ & & 100 \\
\hline
\end{tabular}




\begin{tabular}{|c|c|c|c|}
\hline Cable & $\begin{array}{l}3 \mathrm{~m} 12 \text { AWG pot } \\
\text { conductor }\end{array}$ & 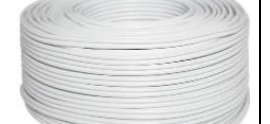 & 37 \\
\hline $\begin{array}{l}\text { Single } \\
\text { phase plug }\end{array}$ & $\begin{array}{l}\text { Round plug with } \\
\text { three terminals }\end{array}$ & & 64 \\
\hline $\begin{array}{l}\text { Iron } \\
\text { laminate }\end{array}$ & $1 \mathrm{~m}^{2}$ Iron laminate & & 70 \\
\hline $\begin{array}{l}\text { Screws } \\
1 / 4^{\prime \prime}\end{array}$ & $\begin{array}{l}3 \text { Hex head screw } \\
1 / 4 \mathrm{X} 1 \frac{1}{2},\end{array}$ & & 45 \\
\hline Welding & $\begin{array}{ll}4 & \text { welding } \\
\text { electrodes } & 308\end{array}$ & AW[L E.3010.46 & 44 \\
\hline Resistance & $\begin{array}{l}\text { Electric resistance } \\
\text { 800watts }\end{array}$ & & 330 \\
\hline $\begin{array}{l}\text { Galvanize } \\
\text { d nipples, } \\
\text { plugs and } \\
\text { reduction } \\
\text { bush }\end{array}$ & $\begin{array}{c}\text { Elements for } \\
\text { vapor pressure test }\end{array}$ & & 120 \\
\hline \multicolumn{3}{|c|}{ TOTAL } & 780 \\
\hline
\end{tabular}

\section{CONSTRUCTION PROCEDURE}

The water tube tank was built with 10 gauge stainless steel sheet (0.135in or $3.429 \mathrm{~mm}$ thickness), with hemispherical caps and welded with a 308 coated electrode. The electrical resistance installation is located around the tubular located in the lower part as shown in figure 9. Therefore, Newton's law of cooling or Newtonian cooling establishes that the rate of heat loss from a body is proportional to the difference in temperature between the body and its surroundings. It was determined experimentally by
Isaac Newton analyzing the cooling process and for him the cooling rate of a warm body in a colder environment $\mathrm{Tm}$, whose temperature is $\mathrm{T}$, is proportional to the difference between the instantaneous temperature of the body and that of the environment. When the temperature difference between a body and its environment is not too great, the heat transferred in the unit of time to the body or from the body by conduction, convection and radiation is approximately proportional to the difference in temperature between the body and the external environment. [6]

$$
\begin{aligned}
& \frac{d Q}{d t}=\alpha A\left(T-T_{a}\right) \\
& d Q=-m c_{e} d T \\
& \frac{-m c_{e} d T}{d t}=\alpha A\left(T-T_{a}\right) \\
& \text { sea } \quad k=\frac{\alpha A}{m c_{e}} \\
& \frac{d T}{d t}=-k\left(T-T_{a}\right) \\
& \int_{T_{0}}^{T} \frac{d T}{\left(T-T_{a}\right)}=-k \int_{0}^{t} d t \\
& \ln \left(T-T_{a}\right)=-k t+\ln \left(T_{0}-T_{a}\right) \\
& T=T_{a}+\left(T_{0}-T_{a}\right) e^{-k t}
\end{aligned}
$$

Where:

$\mathrm{A}=$ Body area

$\alpha=$ Coefficient of heat exchange, it depends on the geometric shape of the body.

$\mathrm{T}=$ Body temperature at time $\mathrm{t}$

$\mathrm{Ta}=$ ambient temperature

$\mathrm{Q}=$ Heat transferred

$\mathrm{m}=$ Mass

$\mathrm{Ce}=$ Specific heat

$\mathrm{t}=$ Time

$\mathrm{T} 0$ = Initial body temperature 


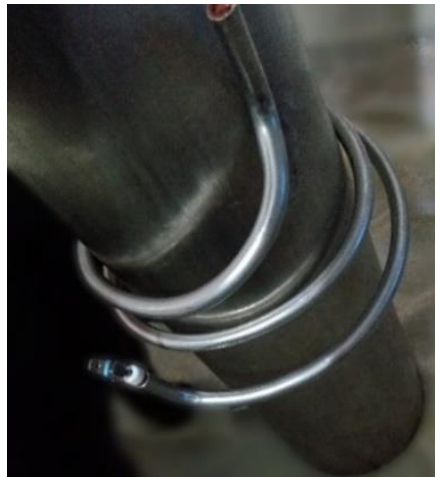

Figure 9 Electrical resistance installation

Once the resistance was installed, the fiberglass was placed, which will allow to maintain the heat generated by the resistance and avoid heat losses, as shown in figure 10. Afterwards, the cap made with stainless steel sheet was placed, in the upper outlet of the tubular was placed the analog pressure gauge, in the first lower outlet a galvanized male plug was installed connected with a terminal nipple to seal and prevent water or steam leaks, during the hermeticity and steam obtaining tests, A temperature thermometer was placed in the second lower outlet of the tubular, assembling the connection with a galvanized bush type reduction, a bell nipple with a gasket, a coupling and a brass bell nipple.

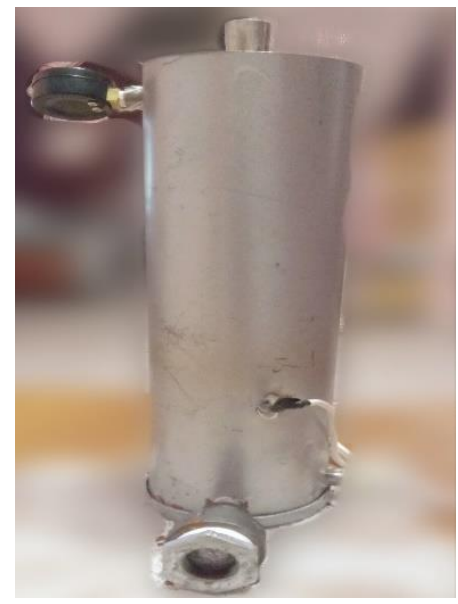

Figure 10 Finished prototype

\section{RESULTS}

Once the construction of the generator was completed, the pertinent tests were carried out to detect and thus be able to correct water or steam leaks, see figure 11 , thanks to the measurement equipment that was adapted to obtain the temperature reading, the following data were collected ( Table 1, graph 1) where the relationship between the time it takes for the water to reach its maximum temperature of $100^{\circ} \mathrm{C}$ is shown, it is observed that during the first 20 minutes the water remains at room temperature, but that from minute 25 the temperature begins to rise rapidly (graph1) and that from minute 45 the water reaches its maximum temperature starting with the boiling point.

Table 1 Heating

\begin{tabular}{|c|c|}
\hline \multicolumn{2}{|c|}{ HEATING } \\
\hline Minutes & ${ }^{\circ} \mathbf{C}$ \\
\hline 5 & 25 \\
\hline 10 & 26.8 \\
\hline 15 & 28 \\
\hline 20 & 31.9 \\
\hline 25 & 49.2 \\
\hline 30 & 68.5 \\
\hline 35 & 86 \\
\hline 45 & 100 \\
\hline
\end{tabular}

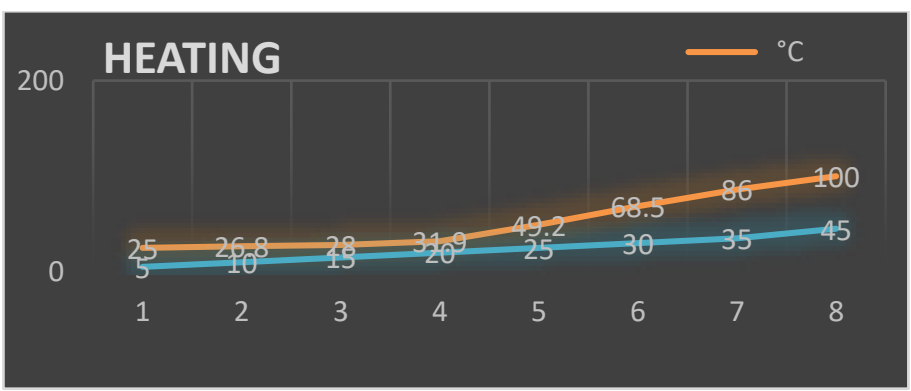

Graph 1 Heating

For the soap paste drying process, it is important to take into account the cooling time, therefore the data was collected (table 2 , graph 2) where we observe that the time it takes for the water to return to room temperature is longer. In the first 30 minutes we can still have the temperature required for the process.

Table 2 Cooling

\begin{tabular}{|c|c|}
\hline \multicolumn{2}{|c|}{ COOLING } \\
\hline Minutes & ${ }^{\circ} \mathbf{C}$ \\
\hline 15 & 100 \\
\hline 19 & 89.8 \\
\hline 25 & 78.5 \\
\hline 29 & 70.2 \\
\hline 32 & 66 \\
\hline 37 & 60.9 \\
\hline 43 & 55 \\
\hline 45 & 48.4 \\
\hline 49 & 37.1 \\
\hline 55 & 25 \\
\hline
\end{tabular}




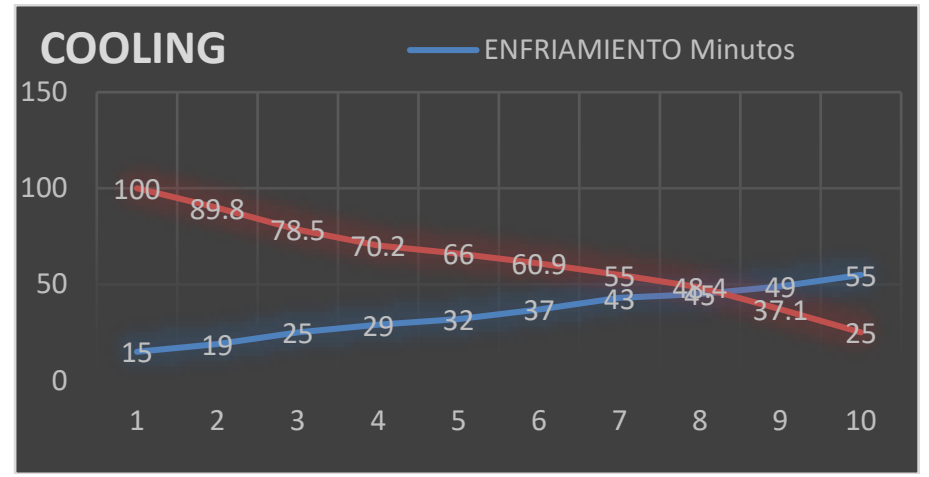

Graph 2 Cooling

The temperature and the amount of steam that this prototype generates is adequate and necessary to carry out the drying process of soap paste, fulfilling the main objective.

The results obtained were satisfactory for this steam generator prototype that achieves a temperature of $100^{\circ} \mathrm{C}$, a pressure of $0.7 \mathrm{bar}, 12.5 \mathrm{psi}$. and a current consumption of 7Amp. At 127 volts, see figure 11.

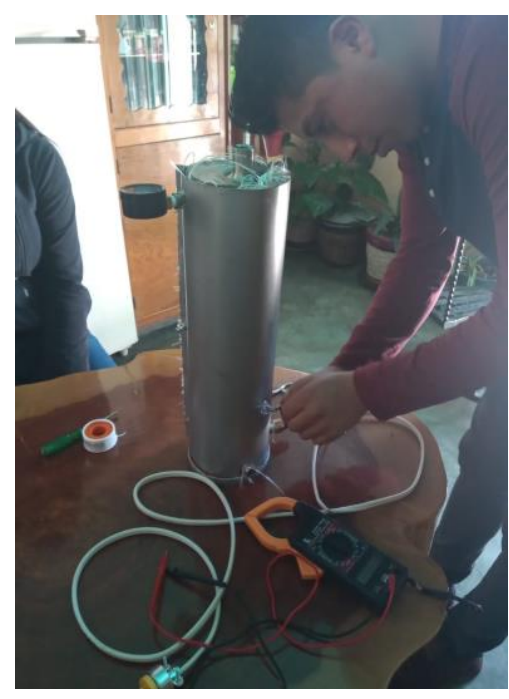

Figure 11 Final tests

\section{CONCLUSION}

The project requires a constant steam pressure for a good soap drying process, it is necessary to have a certain temperature, if the temperature exceeds the limit required for the paste generation process, it can cause poor drying for the soaps, It can evaporate very quickly the water inside the container causing it to burn and in some cases cause accidents, in addition, a high temperature can generate excess steam and if we do not have a relief valve this can cause the container to explode causing accidents to people or the installations.

To avoid this, an electronic control will be designed in a second stage based on a temperature sensor programmed in Labview, this will allow us to control and monitor the temperature of the resistances so that when it exceeds the limit, the resistances turn off, and when lower the temperature, the resistance turns on again and continue with the process,

For the moment, in this first stage, with the results obtained in this prototype, it is possible to meet the objectivep of generating the steam that is needed for a pilot soap production plant, in the part of the drying of pasta, so this stage remains concluded and will continue with the other components that make up the production system.

This proposed system is a new model.

\section{REFERENCES}

[1] Babor, Joseph A.and and Ibarz, José (1978). Modern general chemistry (volume I). Havana: Scientific-Technical Editor [2] Mier, S, (2013). Thermodynamic analysis and basic calculation of the boiler and the cooling tower of the robla thermal power plant, Department of Thermal and Fluid Engineering. Thermal Engineering Area. Higher Polytechnic School. University Carlos III of Madrid.

[3] Varetto, R. H. (2011), Industrial electrical and combustion heating, Alsina Bookstore and Publishing, Buenos Aires.

[4] Mathews, J and Fink, K. (2017), Numerical methods with Matlab 3rd Edition, Prentice Hall.

[5] Chapra, S. and Canele (2019), Numerical methods for engineers 6th Edition, Mc Graw Hill.

[6] Young, H. D., Freedman, R. A., \& Flores, V. A. (2009). University Physics. Sears-Zemansky (Vol 1). Mexico: Pearson Education.

[7] Ojeda, A. (2014), Control and instrumentation of a steam generator for the petrochemical industry, Universidad Nacional Autónoma de México.

[8] Uceda, J. (2019) Basic Guide to Boilers, Viessman S.L.

\section{AUTHORS}

First Author - M.C. José Luis Hernández Corona research professor Industrial Maintenance Engineering, Technological University of Tlaxcala

coronaluis@uttlaxcala.edu.mx

Second Author - Ernesto Mendoza Vazquez; Teacher researcher of Time Complete in Industrial Maintenance Engineering at the Technological University of Tlaxcala, Desirable Profile PROMEP as well as academic corps in industrial maintenance, with a master's degree in Advanced Manufacturing and graduate in Electronics. emendozavz@uttlaxcala.edu.mx 
Third Author - Hilda Sánchez Lima engineering student in industrial maintenance at the technological university of Tlaxcala hilda.s12698@gmail.com

Fourth Author Verenice Fragoso Parra engineering student in industrial maintenance at the technological university of Tlaxcala vere99parra@gmail.com
Fifth Author Guadalupe Adriana Espinoza Peralta engineering student in industrial maintenance at the technological university of Tlaxcala

gaep46@gmail.com

Sixth Author José Armando Olivares Bautista engineering student in industrial maintenance at the technological university of Tlaxcala armando28olibas@gmail.com 